\title{
Implementation of Fingerprint based Student Attendance System with Notification by GSM Module
}

\author{
Zin Nwe Soe \\ Department of Electronic \\ Engineering \\ Technological University \\ Thanlyin, Myanmar
}

\author{
Dr. Aye Mya Win \\ Department of Electronic \\ Engineering \\ Technological University \\ Thanlyin, Myanmar
}

\author{
Daw Thae Hsu Thoung \\ Department of Electronic \\ Engineering \\ Technological University \\ Thanlyin, Myanmar
}

\begin{abstract}
Attendance and academic success are directly related in educational institutions. The continual absence of students in lecture, practical and tutorial is one of the major problems of decadence in the performance of academic. The authorized person needs to prohibit truancy for solving the problem. In existing system, the attendance is recorded by calling of the students' name, signing on paper, using smart card and so on. These methods are easy to fake and to give proxy for the absence student. For solving inconvenience, fingerprint based attendance system with notification to guardian is proposed. The attendance is recorded using fingerprint module and stored it to the database via SD card. This system can calculate the percentage of attendance record monthly and store the attendance record in database for one year or more. In this system, attendance is recorded two times for one day and then it will also send alert message using GSM module if the attendance of students don't have eight times for one week. By sending the alert message to the respective individuals every week, necessary actions can be done early. It can also reduce the cost of SMS charge and also have more attention for guardians. The main components of this system are Fingerprint module, Microcontroller, GSM module and SD card with SD card module. This system has been developed using Arduino IDE, Eclipse and MySQL Server.
\end{abstract}

Keywords: fingerprint module, GSM module, microcontroller, Eclipse, MySQL Server

\section{INTRODUCTION}

Attendance system is important role for any organization such as office, companies, schools, universities and so on. In conventional attendance system, the teachers either call the name or identity number of the students or allow the students to sign on paper. It is not convenient to track the attendance for the increase number of students. So, it can have the problems such as proxy attendance and time consuming. The traditional system can also have the difficulty for manipulating the stationery materials of the attendance record and posting the attendance report to guardians. Biometrics authentication is used for taking attendance of students. The most common used of biometrics authentication methods are fingerprint, facial, iris, voice authentication and so on. In this system, fingerprint authentication method is used to record attendance because it is easy to use, more accuracy and cost effective. The attendance management system is also involved alerting system to perform together with guardians and the authorized person for the students to attend the class regularly. The main purpose of this research work is to make the attendance management system more efficient, secure, portable, easy to use and less time consuming.

\section{LITERATURE REVIEW}

A number of existing works focus on the application of various methods and principles to effectively monitor the attendance of students. Design and development of smart student management system was proposed. The system consists of two parts, one is fingerprint based student attendance system and another one is notice board [3]. A wireless attendance system using Zigbee technology that authenticates using fingerprints of an individual. The system is mentioned with transmitter and receiver. The transmitter comprises controller, fingerprint module section, LCD, keypad and PC is the receiver. The system takes attendance records with fingerprint module and updates the database attendance records of students via Zigbee module [8]. RFID based student attendance system with notification to parents was designed. This paper presents a design of an automatic attendance system for both students and professor with parents notification sent via GSM [11].

\section{SYSTEM DESCRIPTION}

The block diagram of the system is shown in Figure 1.

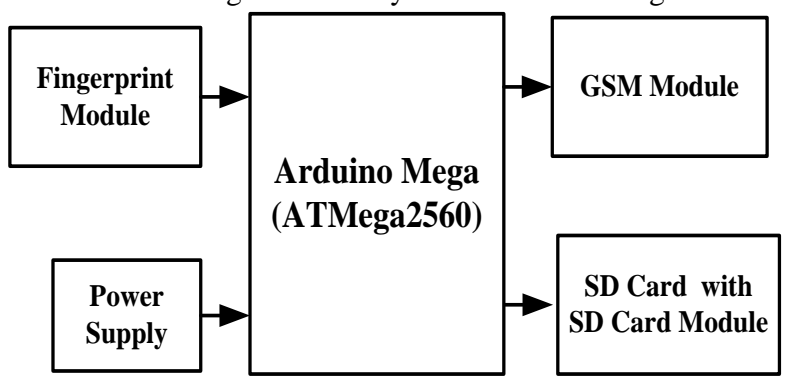

(a) 


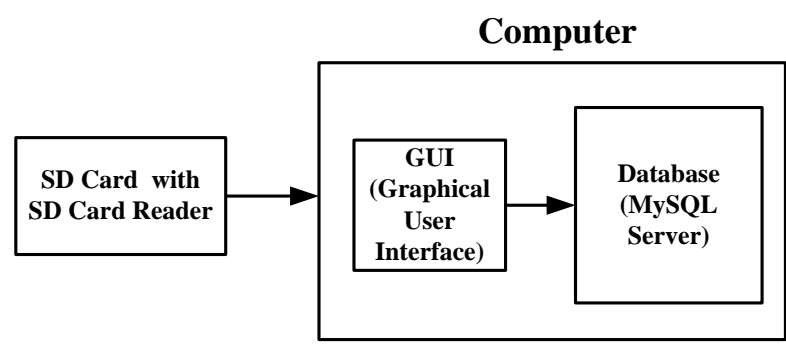

(b)

Figure 1. Block Diagram of the System

This system consists two parts. One part of the system is taking attendance using fingerprints of students and storing data to SD card with text file and sending message after extracting absence from SD card. Another one is storing the attendance via SD card and calculating the percentage of attendance.

\subsection{System Schematic Diagram}

The schematic diagram is depicted in Figure 2. The circuit diagram illustrates interfacing Arduino Mega (ATmega 2560) with GSM module (SIM900A), fingerprint module, SD card module and two LEDs. It allows from 7volts to 12volts for the power. TX (transmit) and RX (receive) of SIM900A is connected with 2 and 3 pins of Arduino Mega. Pin 10 and 11 are used to connect with transmit and receive pins of fingerprint module. The pins of SD card module are connected with 50, 51, 52 and 53 pins of Arduino Mega. The black color of the wire is defined for the ground (GND) and the red color of the wire is defined for the voltage $\left(\mathrm{V}_{\mathrm{CC}}\right)$. Two LEDs are used for showing the processing time of fingerprint. These are connected with 6 and 7 pins of the Arduino Mega.

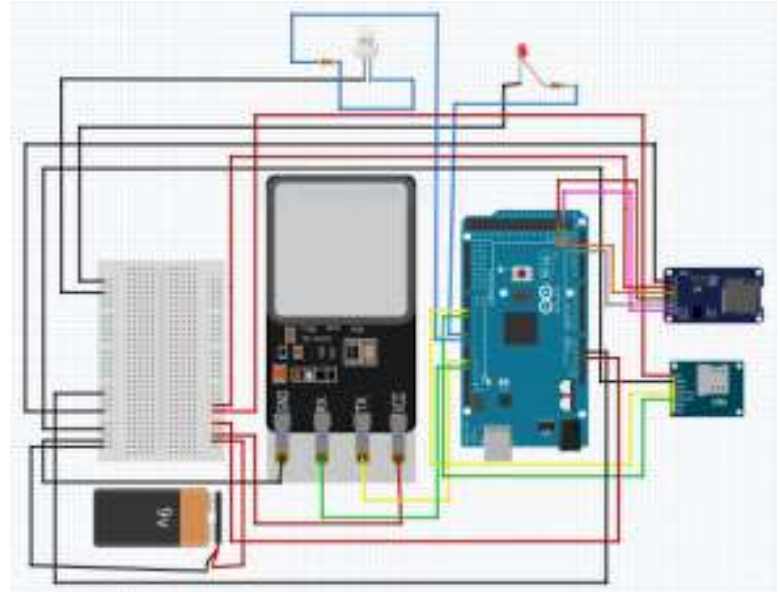

Figure 2. Schematic Diagram of the System

\section{HARDWARE AND SOFTWARE DESCRIPTION}

To reduce the complexity of the design process, simple algorithms, low cost and commercially available devices have been used to implement the system.

\subsection{Fingerprint Reader}

Fingerprint authentication is used for the student attendance system. It consists of two parts. One is enrollment and another one authentication. During enrollment, the fingerprint of the student is captured using fingerprint reader and the unique features are extracted and stored in the database as the template with the student ID. In the processing of authentication, the fingerprint of student is captured again and compared with the extracted features already existing in the database for determining match or mismatch. In this system, Biovo-C3 fingerprint identification integrated reader is used to capture fingerprints as shown in Figure 3. Fingerprint module mainly has three types of fingerprint sensors like optical fingerprint sensor, ultrasonic fingerprint sensor and capacitive fingerprint sensor. The sensor type of Biovo-C3 fingerprint reader is high-definition optical sensor. This reader can store 200 fingerprints. It has 256 bytes for fingerprint extraction template size and 512 bytes fingerprint match template size. This reader is integrated image collecting and algorithm chip together with a tiny configuration of $18.5 \mathrm{~mm} \times$ $14.6 \mathrm{~mm}$.

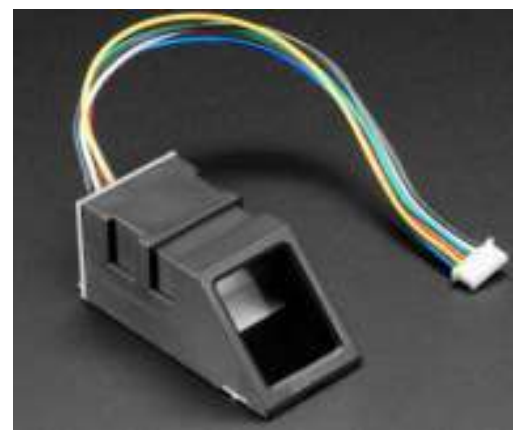

Figure 3. Biovo-C3 Fingerprint Reader

\subsection{GSM SIM 900A Modem}

A GSM SIM 900A modem is used to send alert messages to guardians as shown in Figure 4. A GSM modem is a specialized type of modem which accepts a SIM card, and operates over a subscription to a mobile operator, just like a mobile phone. From the mobile operator perspective, a GSM modem looks just like a mobile phone. While these GSM modems are most frequently used to provide mobile internet connectivity, many of them can also be used for sending and receiving SMS (short message service) and MMS (multimedia messaging service) messages. SIM900 is designed with a very powerful single-chip processor integrating AMR926EJ-S core. The SIM900A is a complete Quad-band GSM/GPRS solution in a SMT module which can be embedded in the customer applications. Featuring an industry-standard interface, the SIM900 delivers GSM/GPRS $850 / 900 / 1800 / 1900 \mathrm{MHz}$ performance for voice, SMS, Data, and Fax in a small form factor and with low power consumption. With a tiny configuration of $24 \mathrm{~mm} \times 24 \mathrm{~mm} \times 3$ $\mathrm{mm}$, SIM900 can fit almost all the space requirements in M2M application, especially for slim and compact demand of design. AT commands are instructions used to control a modem. AT is the abbreviation of Attention. Every command line starts with "AT" or "at". That's why modem commands are called AT commands. Many of the commands are called AT commands that are used to control dial-up modems such as ATD (Dial), ATA (Answer), ATH (Hook control) and 
ATO (Return to online data state). These commands are also supported by GSM/GPRS modems and mobile phones. The SMS-related commands are AT+CMGS (Send SMS message), AT+CMSS (Send SMS message from storage), AT+CMGL (List SMS messages) and AT+CMGR (Read SMS messages).

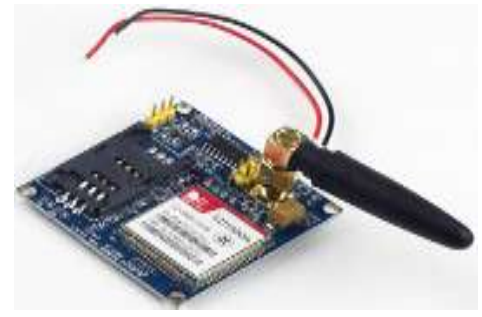

Figure 4. GSM ( SIM 900A) Modem

\subsection{Arduino Mega (ATmega 2560)}

Arduino is a software company, project, and user community that designs and manufactures computer open-source hardware, open-source software and microcontroller-based kits for building digital devices and interactive objects that can sense and control physical devices. These systems provide sets of digital and analog I/O pins that can interface to the various expansion boards and other circuits. The boards feature serial communication interfaces, including Universal Serial Bus (USB) on some models, for loading programs from personal computers. For programming the microcontrollers, the Arduino project provides an integrated development environment (IDE) based on Arduino programming language which is controlled by a set of $\mathrm{C} / \mathrm{C}++$ functions. The Arduino Mega is a microcontroller board based on the ATmega2560. It has 54 digital input/output pins (of which 14 can be used as PWM outputs), 16 analog inputs, 4 UARTs (hardware serial ports), a $16 \mathrm{MHz}$ crystal oscillator, a USB connection, a power jack, an ICSP header, and a reset button. The board can operate on an external supply of 6 to 20 volts. If supplied with less than $7 \mathrm{~V}$, however, the $5 \mathrm{~V}$ pin may supply less than five volts and the board may be unstable. If using more than $12 \mathrm{~V}$, the voltage regulator may overheat and damage the board. The recommended range is 7 to 12 volts. The Arduino Mega (ATmega2560) is shown Figure 5.

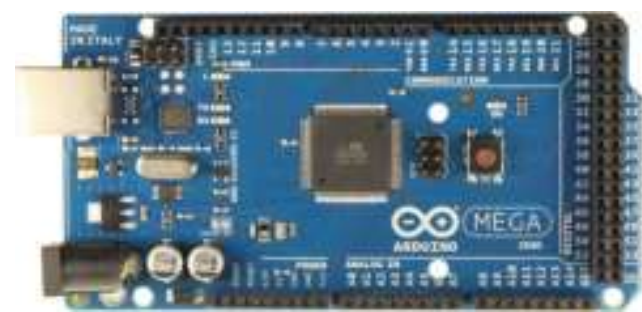

Figure 5. Arduino Mega (ATmega2560)

\subsection{SD Card Module}

The SD card module is a sample solution for transferring data to and from a standard SD card. It used to store the attendance and transfer to database of PC in this system. The pin out is directly compatible with Arduino, but can also be used with other microcontrollers. It allows to add the mass storage. The module has SPI interface which is compatible with any SD card and it use $5 \mathrm{v}$ or $3.3 \mathrm{v}$ power supply which is compatible with Arduino mega. The communication between the microcontroller and SD card uses SPI, which takes place on digital pins 50, 51, 52 for the Arduino Mega. Additionally, another pin must be used to select the SD card. SS pin of SD card module is connected with pin 53 on the Arduino Mega. The size of module is $20 \times 28 \mathrm{~mm}$. This module is shown in Figure 6 .

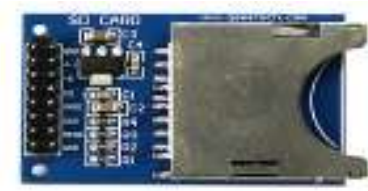

Figure 6. SD Card Module

\subsection{Software Description}

To complete this system, Eclipse, MySQL server and phpMyAdmin are used. Eclipse is an integrated development environment (IDE) used in computer programming. Eclipse is written mostly in Java and its primary use for developing Java applications, but it may also be used to develop applications in other programming languages. Java is used to develop this system. MySQL is a relational database management system (RDBMS) based on SQL (Structured Query Language) and phpMyAdmin is a web-based interface to a MySQL server. It can be created new databases import table using phpMyAdmin.

\section{TESTS AND RESULTS}

The working diagram of the system is shown in Figure 7. In the system, the students are not allowed to take the attendance if the teacher does not reach in the class because the fingerprint of teacher is set as a password to secure for the students. After taking attendance, the teacher or authorized person must take SD card to store attendance in the database of PC. GSM module will also send alert message to guardians' mobile phone for the students don't enough the percentage of attendance weekly. The alert message of guardians' mobile is shown in Figure 8.

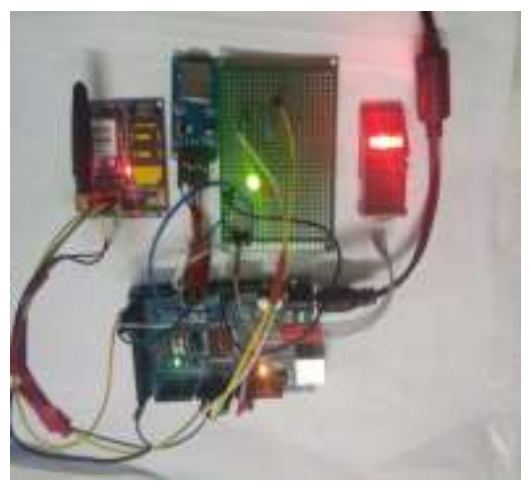

Figure 7. The Working Diagram of the System 


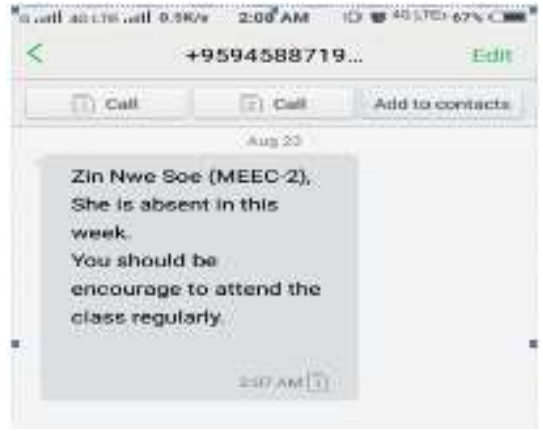

Figure 8. Alert Message Display in Guardians’ Mobile

In the system, the data of the students from SD card are copied in the database with the date. It can store data for long time. This system can also calculate the percentage of students with no time consuming. If the data are not need, the authorized person can edit the database from phpMyAdmin. The table in database of fingerprint attendance system is shown in Figure 9. The calculating of the attendance percentage is shown in Figure 10. The editing to database using phpMyAdmin is shown in Figure 11.

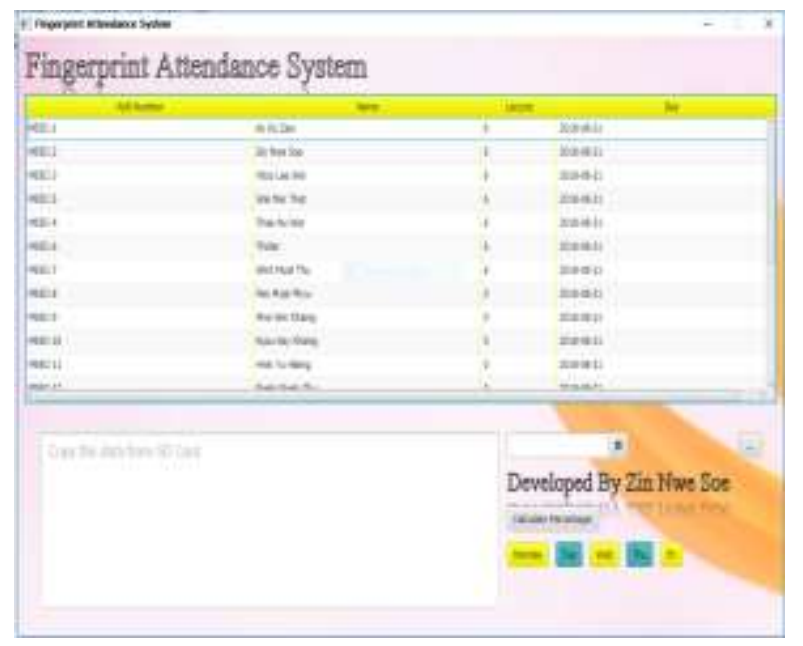

Figure 9. Table of Fingerprint Attendance System

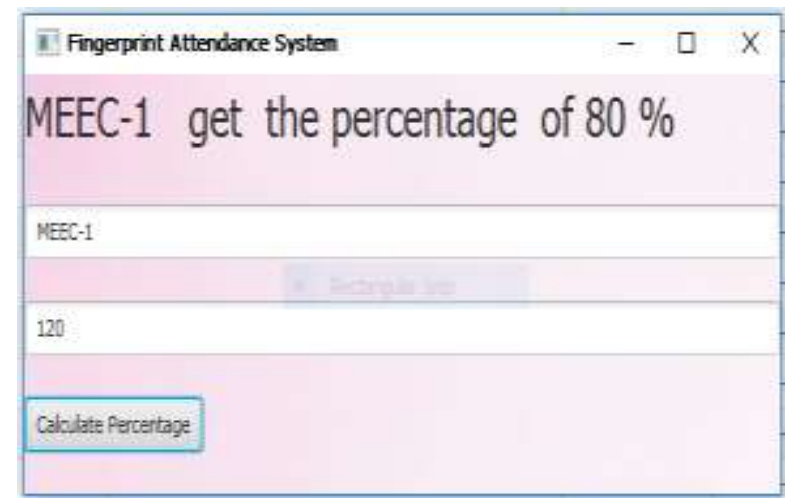

Figure 10. Calculating the Percentage of Student Attendance

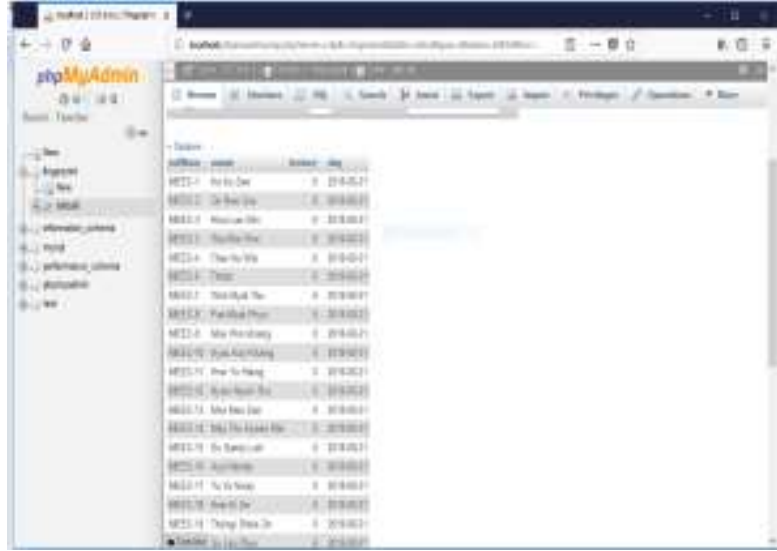

Figure 11. Editing the database of Attendance System

\section{CONCLUSION}

Attendance system could not only speed up the process taking attendance but also reduce the error rate and produce faster verification process of authenticating student attendance. This system calculates the attendance of students and sends alert message for the absence students to relevant guardians' mobile phone. This system can also store the data of students for long time.

\section{ACKNOWLEDGEMENTS}

Firstly, the author would like to acknowledge Dr. Thein Gi, Rector of Technological University (Thanlyin), for her kind permission to carry out this research work. The authors would like to thank many colleagues from digital image processing research group of Department of Electronic Engineering of Technological University (Thanlyin). The author particularly wishes to acknowledge all the teachers from Department of Electronic Engineering, Technological University (Thanlyin), for their support, encouragement and invaluable guidance in preparation of this research. The authors would like to express their thanks to all persons who have given support during the preparation period of this research work.

\section{REFERENCES}

[1] Dhiman Kumar Sarker, Nafize Ishtiaque Hossain, Insan Arafat Jamil. 2016 "Design and Implementation of Smart Attendance Management System Using Multiple Step Authentication", International Workshop on Computational Intelligence(IWCI), 12-13.

[2] Mr. Sopan D.Borale, Ms. Poonam G.Chaudhari, Ms. Vaijanti B.Patil, Ms. Apurva D.Shingne, Prof.G.N.Dhoot. 2016. "Fingerprint Based Attendance Management System with SMS Alert to Parents", International Journal Research in Advent Technology (IJRAT) (E-ISSN: 23219637) Special Issue National Conference "CONVERGENCE 2016".

[3] Rakib-UI Hasan, Md. Akibul Azam, Md. Riifat Rahman, Abdulian-AL Mamum, Md. Saniat Rahman Zishan. 2017. "Design and Development of Smart Student management System ", International Journal of Modern Education Research, ISSN: 2375-3781.

[4] Karthik Krishnamurthi, S.Irudaya Mary, B.N. Sumalatha, Adler Pereira. 2015. "Fingerprint Based Attendance System", International Journal of Advanced Research in Computer and Communication Engineering, Vol.4, Issue 3. 
[5] Nur Izzti Zainal, Khairul Azami Sidek, Teddy Surya Gunawan, Hasmah Mansor, Mira Kartiwi. 2014. "Design and Development of Portable Classroom Attendance System Based on Arduino and Fingerprint Biometric", Information and Communication Technology for the Muslim World (ICT4M), $5^{\text {th }}$ International Conference.

[6] Hitesh Walia, Neelu Jain. 2016. "Fingerprint Based Attendance System Using LabVIEW and GSM", International Journal of Innovative Research in Science, Enginering and Technology, Vol.5, Issue 7.

[7] Ravishankar Yadav, Sumita Nainan. 2014. "Design Based Student Attendance System with Notification to Parents Using GSM", International Journal of Engineering Research \& Technology (IJERT), ISSN:2278-0181, Vol.3, Issue 2.

[8] Akshay v. Bhoyar, Shruti A. Borgave, A.S Bhandare. 2014. "Wireless Fingerprint Based Attendance System Using Zigbee Technology", International Journal of Innovative Resarch In Technology, ISSN: 23496002, Volume 1, Issue 11.

[9] Vishal Suryawnshi, Kiran Puri, Prashant Devkar, Dr.K.S Tiwari. 2017 "Attendance Monitoring System Automation Using Fingerprint Module", International Journal of Electrical, Electronics and Computer Systems (IJEECS), ISSN(Online) 2347-2820, Volume-5, Issue-1.

[10] Shweta K Nandya, Baswaraj Gadgey, Veeresh Pujari. 2017. "RFID and Fingerprint Based Smart Attendance System", International Journal for Research in Applied Science \& Engineering Technology (IJRASET), Volume 5, Issue VI, ISSN: 2321-9653.

[11] Ravishankar Yadav, Sumita Nainan.2014. "Design of RFID Based Student Attendance System with Notification to Parents Using GSM", International journal of Engineering Research \& Technology (IJERT) ,ISSN:2278-0181, Vol.3 Issue 2. 